\title{
Numerical modelling of transient flows with high sediment concentrations
}

\author{
B. J. Dewals ${ }^{1,2}$, S. Erpicum ${ }^{1} \&$ M. Pirotton ${ }^{1}$ \\ ${ }^{1}$ Department ArGEnCo, University of Liege, Belgium \\ ${ }^{2}$ Fund for Scientific Research F.R.S.-FNRS, Belgium
}

\begin{abstract}
The main purpose of the present paper is to describe and discuss the development, validation and application of a numerical model designed to handle transient flows with high sediment transport rates. The model considers nonequilibrium transport (i.e. accounting for loading/unloading delay) and is numerically as well as physically totally coupled. The closure relations needed to evaluate the exchange fluxes between the fixed bottom and the flowing mixture (erosion and deposition rates) are also detailed in the paper. Finally, the model is validated against experimental data collected in the framework of the European project IMPACT.
\end{abstract}

Keywords: sediment transport, depth-averaged flow modelling, finite volume, erosion rate, dam break on an erodible topography.

\section{Introduction}

Conventional models for flow and sediment transport usually consider a weak numerical and physical coupling between the sub-models for hydrodynamics and for sediment transport. However, in numerous cases of intense transport conditions, such as debris flows but also flows caused by dam breaks occurring in erodible valleys, the above-mentioned loose coupling is not valid. In particular, many historical dam break events in the world are known to have induced highly erosive flows, which in turn caused significant scouring in the downstream valley, both in the floodplains and on other structures (e.g. dam breaching in cascade).

For the purpose of modelling such flows, characterized by extremely high sediment loads, the sub-models for hydrodynamics and sediment transport need 
to be tightly coupled both numerically and physically. The numerical coupling is necessary for the model to be able to handle properly regime changes and moving discontinuities (hydraulic jumps, sediment bores ...), while it leads to genuine challenges in the development of suitable upwind discretization schemes and in terms of required computation time. The physical coupling implies that the momentum balance takes into consideration the effect of sediment concentration on the pressure distribution and on the inertia of the mixture.

In the present model, the momentum equations account explicitly for the concentration in sediments in the flow, hence tightly coupling the dynamics of water and of solid particles. Besides, the present model considers nonequilibrium transport (i.e. accounting for loading/unloading delay). The closure relations needed to evaluate the exchange fluxes between the fixed bottom and the flowing mixture (erosion and deposition rates) are also detailed in the paper, as well as the other main features of the model. Finally, the model is validated against experimental data collected in the framework of a European project.

\section{Model description}

The present model for flow and (equilibrium or non-equilibrium) sediment transport [6] has been entirely derived from the local conservation equations, by application of a depth-averaging operation, and doesn't simply result from a macroscopic approach. Subsection 2.1 presents the conservation laws, while the concentration profile is discussed in subsection 2.2 and the formulation of the diffusive terms in subsection 2.3. The closure relations required for evaluating the bed shear stress components, as well as the erosion and deposition rates, are detailed respectively in subsections 2.4 and 2.5 .

\subsection{Conservation laws}

As detailed by Dewals [6], the model is based on two mass conservation equations, respectively for the water-sediment mixture and for the transported sediments:

$$
\begin{aligned}
& \frac{\partial}{\partial t}[h(1+\Delta s \bar{C})]+\frac{\partial}{\partial x}[h(1+\Delta s \bar{C}) \bar{u}]+\frac{\partial}{\partial y}[h(1+\Delta s \bar{C}) \bar{v}]=[1+\Delta s(1-p)] \frac{e_{\mathrm{b}}}{1-p} \\
& \frac{\partial}{\partial t}(h \bar{C})+\frac{\partial}{\partial x}(h \bar{u} \bar{C})+\frac{\partial}{\partial y}(h \bar{v} \bar{C})=-\left[\frac{\partial}{\partial x}\left(h \frac{v_{\mathrm{T}}}{\sigma_{\mathrm{T}}} \frac{\partial \bar{C}}{\partial x}\right)+\frac{\partial}{\partial y}\left(h \frac{v_{\mathrm{T}}}{\sigma_{\mathrm{T}}} \frac{\partial \bar{C}}{\partial x}\right)\right]+e_{\mathrm{b}},
\end{aligned}
$$

and two momentum equations, written for the water-sediment mixture:

$$
\begin{gathered}
\frac{\partial}{\partial t}\left(\rho_{\mathrm{m}} h \bar{u}\right)+\frac{\partial}{\partial x}\left(\rho_{\mathrm{m}} h \bar{u}^{2}\right)+\frac{\partial}{\partial y}\left(\rho_{\mathrm{m}} h \bar{u} \bar{v}\right)+\frac{\partial}{\partial x}\left(\rho_{\mathrm{m}} g \sin \theta_{z} \frac{h^{2}}{2}\right)+\rho_{\mathrm{m}} h g \sin \theta_{z} \frac{\partial z_{\mathrm{b}}}{\partial x} \\
=\rho_{\mathrm{w}}[1+\Delta s(1-p)] \frac{e_{\mathrm{b}}-\left|e_{\mathrm{b}}\right|}{2(1-p)} \bar{u} \beta+\rho_{\mathrm{m}} g h \sin \theta_{x}+\tau_{\mathrm{b} x}+\frac{\partial h \overline{\sigma_{x}}}{\partial x}+\frac{\partial h \overline{\tau_{x y}}}{\partial y}
\end{gathered}
$$


and

$$
\begin{gathered}
\frac{\partial}{\partial t}\left(\rho_{\mathrm{m}} h \bar{v}\right)+\frac{\partial}{\partial x}\left(\rho_{\mathrm{m}} h \bar{u} \bar{v}\right)+\frac{\partial}{\partial y}\left(\rho_{\mathrm{m}} h \bar{v}^{2}\right)+\frac{\partial}{\partial y}\left(\rho_{\mathrm{m}} g \sin \theta_{z} \frac{h^{2}}{2}\right)+\rho_{\mathrm{m}} g h \sin \theta_{z} \frac{\partial z_{\mathrm{b}}}{\partial y} \\
=\rho_{\mathrm{w}}[1+\Delta s(1-p)] \frac{e_{\mathrm{b}}-\left|e_{\mathrm{b}}\right|}{2(1-p)} \bar{v} \beta+\rho_{\mathrm{m}} g h \sin \theta_{y}+\tau_{\mathrm{b} y}+\frac{\partial h \overline{\tau_{x y}}}{\partial x}+\frac{\partial h \overline{\sigma_{y}}}{\partial y} .
\end{gathered}
$$

Besides, the evolution of the bed elevation is governed by the Exner equation:

$$
\frac{\partial}{\partial t}\left[(1-p) z_{\mathrm{b}}\right]+\frac{\partial q_{\mathrm{b} x}}{\partial x}+\frac{\partial q_{\mathrm{b} y}}{\partial y}=-e_{\mathrm{b}} .
$$

The solid discharges $q_{\mathrm{b} x}$ and $q_{\mathrm{b} y}$ may represent both equilibrium solid transport (such as bed load) and a gravity-induced contribution to the solid transport $[6,9]$.

The main symbols used above are defined in section 5. The following formulation for the density of the mixture has been exploited to derive the conservation equations (1)-(4):

$$
\rho_{\mathrm{m}}=\rho_{\mathrm{w}}(1-C)+\rho_{\mathrm{s}} C=\rho_{\mathrm{w}}[1+(s-1) C]=\rho_{\mathrm{w}}(1+\Delta s C) .
$$

Such a coupled approach is required for applications involving highly transient flows and high transport rates (e.g. induced by dam break and breaching), since in such cases the variation of the density of the water-sediment mixture may not be neglected [10].

The velocity profiles, as well as the profile of concentration along the depth of the flow, have been assumed to be uniform, as discussed hereafter. The evaluation of the bottom shear stress components $\tau_{\mathrm{b} x}$ and $\tau_{\mathrm{b} y}$ is detailed in subsection 2.4 .

Consistently with similar 1D formulations used by other authors, such as Capart [5], the source terms involving the erosion rate in equations (3) and (4) take non-zero values only in the case of deposition. The specific formulation used here is more comprehensively substantiated by Dewals [6]. In equations (3) and (4), $\beta$ designates a correction factor accounting for the difference between the real velocity of sediments before deposition and the depth-averaged flow velocity.

The system of equations (1)-(5) constitutes a non-equilibrium twodimensional extension to the model proposed by previous authors $[5,11,12]$.

Of course, the system (1)-(5) becomes identical to a physically uncoupled model if $\Delta s \bar{C}$ is neglected compared to unity, which may be valid only for low sediment concentrations or for light solid particles.

The presently described mathematical and numerical model is incorporated in the modelling system "WOLF", developed at the University of Liege, which includes a process-oriented hydrological model, a 1D model for river networks as well as 2DH (depth-averaged) and 2DV hydrodynamic models.

\subsection{Concentration and velocity profile}

The theoretical "Rouse profile" is known to develop in a steady and uniform flow with low sediment concentration $(<4 \%)$ [28], whereas the applications of 
the present model cover highly unsteady and non-uniform flows (e.g. dam break and dam breaching flows), for which the concentration profile deviates substantially from the conventional Rouse distribution. Since the real concentration profile remains extremely complex to characterize, a simple uniform distribution has been assumed, consistently with the definition of mature debris flows reported by Takahashi and Nakagawa [23].

Extending the previous assumption to a piecewise constant concentration profile, instead of a uniform one, would require only slight changes in the conservation equations (1)-(4). For instance, if the concentration is assumed to take the constant value $C_{\mathrm{b}}$ for $z_{\mathrm{b}} \leq z \leq z_{\mathrm{b}}+h_{\mathrm{s}}$ (i.e. within a layer of thickness $h_{\mathrm{s}}$ ), then $h \bar{C}$ in the equations simply needs to be replaced by $h_{\mathrm{s}} C_{\mathrm{b}}$ and the updated pressure term: $\left(h^{2} / 2+\Delta s C_{\mathrm{b}} h_{\mathrm{s}}^{2} / 2\right) g \sin \theta_{z}$ must be used instead of the present one: $(1+\Delta s \bar{C}) g \sin \theta_{z}\left(h^{2} / 2\right)$. Several authors have used this assumption, typically keeping a constant value for $C_{\mathrm{b}}$ and calculating the time evolution of the thickness $h_{\mathrm{s}}[11,12]$ or exploiting various empirical closure laws [17].

\subsection{Diffusive terms}

The diffusive terms in equations (2)-(4) may be neglected for most applications governed by highly advective processes, such as flows induced by dam breaks (see section 3). On the contrary, these terms would play a significant part for other applications, such as, for instance, the prediction of sediment deposition patterns in slower flow conditions. In such conditions, the turbulent diffusion terms need to be evaluated. Therefore, the depth-averaged Reynolds stresses $\bar{\sigma}_{x}$, $\bar{\sigma}_{y}$ and $\bar{\tau}_{x y}$ are expressed following the Boussineq's approximation (transposed for a depth-averaged model) [2, 20]:

$$
\frac{\bar{\sigma}_{x}}{\rho}=2\left(v+v_{\mathrm{T}}\right) \frac{\partial \bar{u}}{\partial x}, \quad \frac{\bar{\sigma}_{y}}{\rho}=2\left(v+v_{\mathrm{T}}\right) \frac{\partial \bar{v}}{\partial y}, \quad \frac{\bar{\tau}_{x y}}{\rho}=\left(v+v_{\mathrm{T}}\right)\left(\frac{\partial \bar{u}}{\partial y}+\frac{\partial \bar{v}}{\partial x}\right),
$$

where $v$ represents the molecular kinematic viscosity, while the eddy viscosity $v_{\mathrm{T}}$ is computed by a turbulence closure model $\left(v<<v_{\mathrm{T}}\right)$, such as for instance the depth-averaged $k-\varepsilon$ model developed by Erpicum $[7,8]$.

Besides, the diffusive terms in equation (2) have been expressed according to a Fick law, involving the Schmidt number $\sigma_{\mathrm{T}}$, which usually varies in the range 0.5 to 1 [27] and may be reasonably approached by $\sigma_{\mathrm{T}}=0.5$ [9].

\subsection{Closure relation for bed shear stress}

The bed shear stress evaluation is also influenced by the presence of sediments in the flow, modifying the density of the fluid. According to Takahashi (1991), as 
reported by Leal et al. [17], the bed shear stress in equations (3) and (4)may be expressed by:

$$
\frac{\tau_{\mathrm{b} x}}{\rho_{\mathrm{w}}}=-g \sin \theta_{z} h(1+\Delta s \bar{C}) J_{x} \quad \text { and } \quad \frac{\tau_{\mathrm{b} y}}{\rho_{\mathrm{w}}}=-g \sin \theta_{z} h(1+\Delta s \bar{C}) J_{y}
$$

where $J_{x}$ and $J_{y}$ are the friction slopes calculated by an empirical friction law, such as the Manning formula. Relations (8) are also consistent with the approach used by Valiani and Caleffi [24]. Other more complex formulations are possible as well $[3,23]$.

\subsection{Closure relations for erosion and deposition rates}

Evaluating the net erosion rate $e_{\mathrm{b}}$, equal to the erosion rate $E$ minus the deposition rate $D$, is a key step in the modelling procedure, since all exchanges between the flow layer and the erodible bottom are governed by this parameter. Among various possible approaches [9, 13, 15, 18, 19, 21, 25, 26], a simple reaction equation is used here, assuming that $e_{\mathrm{b}}$ is proportional to the difference between the instantaneous concentration value $\bar{C}$ and the equilibrium concentration $\bar{C}_{*}[4,24]$ :

$$
e_{\mathrm{b}}=E-D=-\frac{\omega_{\mathrm{s}}}{\Lambda}\left(\bar{C}-\bar{C}_{*}\right),
$$

where $\omega_{\mathrm{s}}$ represents the settling velocity and $\Lambda$ is a non-dimensional adaptation length, which may be approximated by means of semi-empirical relations $[1,14]$.

\section{Model validation: dam break flow on an erodible bed}

The model depicted above has been validated by comparison with measured data of an idealized dam break experiment on an erodible topography. The experiments were carried out as a benchmark for validation of numerical codes in the framework of the EU research project IMPACT [16, 22].

\subsection{Description of the benchmark}

The idealized dam break experiments were undertaken in a $2.5 \mathrm{~m}$ long and $10 \mathrm{~cm}$ wide laboratory flume. The bottom of the channel is initially horizontal and consists of a layer of non-cohesive sediments. The solid particles are PVC grains, characterized by a mean diameter of $3 \mathrm{~mm}$ and a relative density of 1.54 .

Initially, a sluice gate defines two distinct zones in the channel. Upstream of the gate, a $10 \mathrm{~cm}$-deep volume of water is at rest, while downstream of the gate, the water level is set at the same level as the surface of the sediment layer, thus completely saturating the erodible bed with water. At the beginning of the experiment, the sluice gate is raised quickly. This operation of opening is achieved within less than $50 \mathrm{~ms}$, so that it may be assumed to be instantaneous in the numerical modelling. 


\subsection{Simulation parameters}

The simulation domain is discretized with 500 cells of $5 \mathrm{~mm}$ each. The time integration is conducted based on an explicit two-step Runge-Kutta scheme, leading to a second order accuracy.

As a results of the extreme transport rates expected to be induced by the dam break flow, the transport capacity formula, used to determine the equilibrium concentration in sediments, is expressed as a function of the mobility parameter $\theta=u / \sqrt{g(s-1) d}$, which characterizes the behaviour of such debris flows [5].

Therefore, the amount of solid materials transported at equilibrium is assumed to be given by a power law of this mobility parameter: $h \bar{C}_{*}=k \theta^{m}$, where $m$ represents the power of the transport capacity formula, while $k$ designates the coefficient of the formula.

The simulations are based on the following values of the parameters involved in the transport capacity law: $k=10^{-3}$ and $m=3$, while the non-dimensional adaptation length $\Lambda$ is simply supposed to be unity. Two different friction coefficients have been tested $(n=0.01 \mathrm{~m} / \mathrm{s}$ and $n=0.02 \mathrm{~m} / \mathrm{s})$, in order to appreciate the sensitivity of the flow and transport rate with respect to the roughness parameter.

\subsection{Results and discussion}

Figure 1 displays the free surface and bottom elevation profiles at four successive times following the idealized dam break: $0.25 \mathrm{~s}, 0.50 \mathrm{~s}, 0.75 \mathrm{~s}$ and

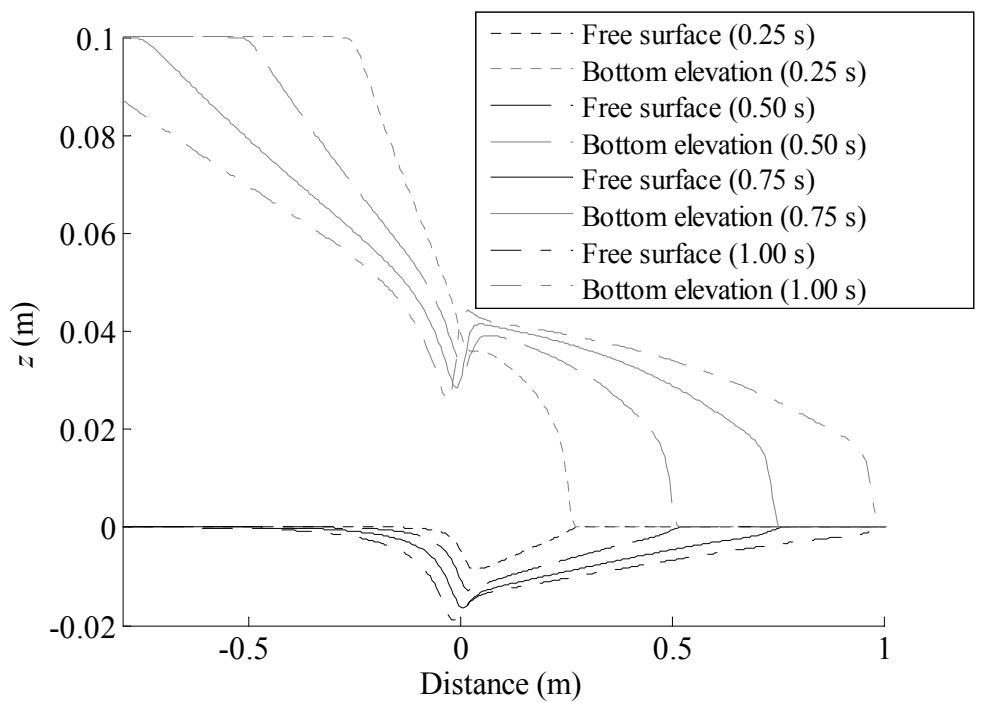

Figure 1: Free surface and bottom elevation profiles at four successive instants following the idealized dam break. 
$1.00 \mathrm{~s}$. Figure 2 represents the time evolution of the free surface elevation and the bed level, both measured during the experiments and simulated with the present model. The results are provided at three points situated respectively at $25 \mathrm{~cm}, 50 \mathrm{~cm}$ and $75 \mathrm{~cm}$ downstream of the initial location of the sluice gate.

(a)

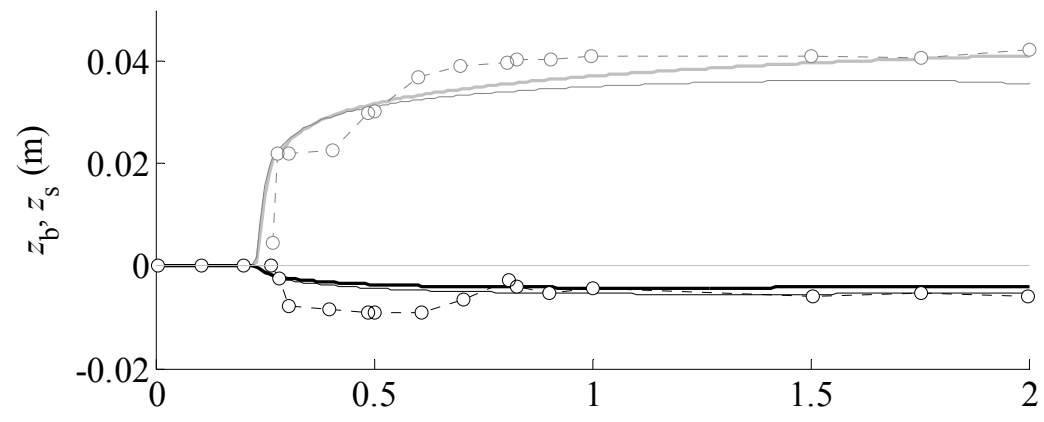

(b)

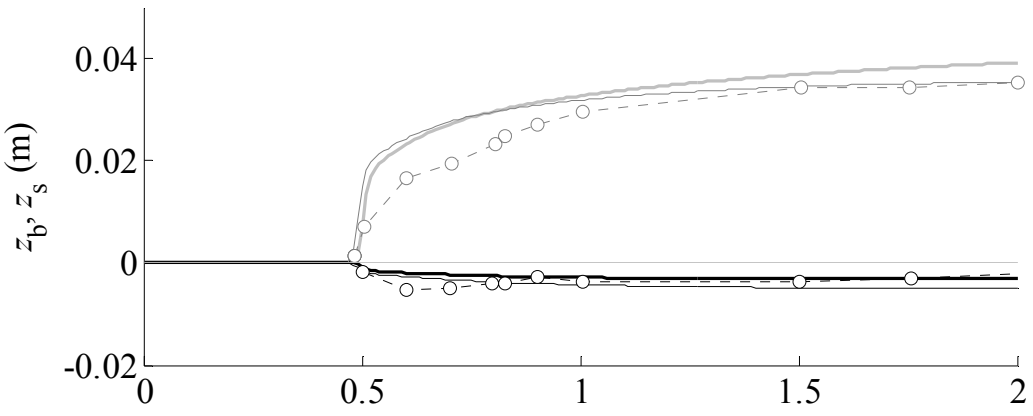

(c)

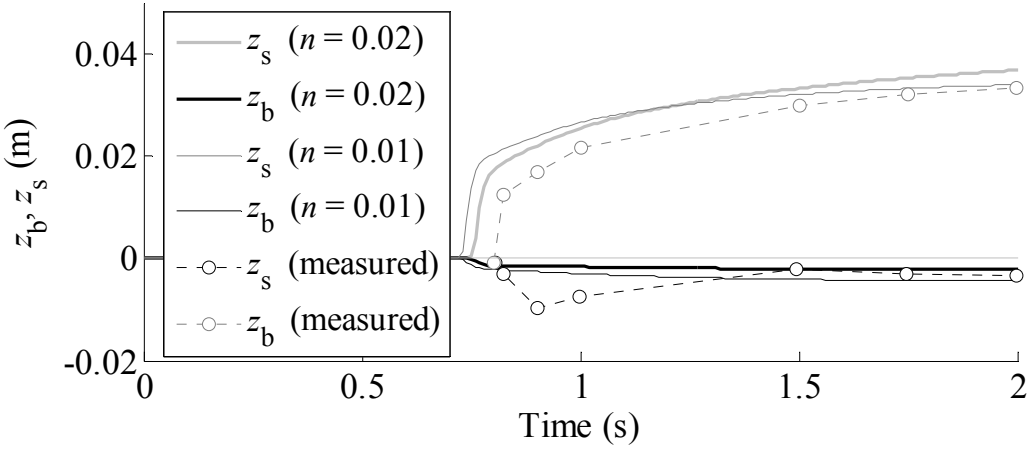

Figure 2: $\quad$ Simulated vs measured time evolution of the bottom elevation and the free surface at the abscissa (a) $0.25 \mathrm{~m}$, (b) $0.50 \mathrm{~m}$, (c) $0.75 \mathrm{~m}$. Comparison of the simulated results for two different roughness coefficients, namely $n=0.01$ and $0.02 \mathrm{~s} / \mathrm{m}^{1 / 3}$.

Figure 2 reveals that the time of arrival of the front is reproduced with a relatively high accuracy. The run based on the higher friction coefficient also 
succeeds in predicting the water level with a reasonable accuracy, while the final scouring depth is reproduced satisfactorily as well. On the other hand, the simulated time evolution of the bottom elevation is monotonous, whereas experimental data reveals intense scouring at the very beginning of the test, followed by an increase in the bottom elevation. This discrepancy results most probably from significant vertical components of velocity in the vicinity of the initial location of the sluice gate. Such vertical velocity components are not considered in the present depth-averaged numerical model. In addition, the experimental measurements are inevitably affected by local errors, especially due to the highly unsteady biphasic flow and transport processes considered here. Those errors remain however hard to quantify close to the initial gate location since the flow is most disturbed in this area and its erosive capacity is also maximum there. The increase in two steps in the measured free surface level is obviously linked to the scouring dynamics. The prediction of the time evolution of the free surface would hence be enhanced by a better simulation of the erosion effects during the first instants.

Figure 2(b) also demonstrates the ability of the model to predict realistically the time of arrival of the front. Moreover, this result shows a rather low sensitivity with respect to the friction coefficient.

The maximum free surface elevation is better reproduced on the basis of the lower friction coefficient. In this respect, the model would advantageously be enhanced by using a formulation of friction law more specifically dedicated to debris flows. In Figure 2(c), the simulated time of arrival of the front appears underestimated, whereas the maximum free surface elevation tends to be overestimated. These observations confirm the need for an enhanced modelling of energy dissipation, possibly considering explicitly the transport rate.

\section{Conclusion}

A model has been presented to simulate flows with sediment transport, potentially in highly unsteady conditions and with high transport rates. In the momentum balance, the density of the fluid (water-sediment mixture) depends explicitly on the concentration in sediments, ensuring thus a physical coupling between the dynamics of water and sediments. The required closure relations for evaluating the bottom shear stress and the erosion rate have been described.

For validation purpose, the model has been tested against experimental data of a benchmark involving highly erosive flows induced by an idealized dam break on a mobile topography. A satisfactory agreement has been shown between the numerical prediction and the measured results, both in terms of free surface elevation and time of arrival of the front.

\section{Symbols}

$\begin{array}{lll}\bar{C} & \text { depth-averaged concentration } & {[-]} \\ e_{\mathrm{b}} & \text { net volumic erosion rate } & {[\mathrm{m} / \mathrm{s}]} \\ h & \text { water depth } & {[\mathrm{m}]}\end{array}$




$\begin{array}{lll}p & \text { bed porosity } & {[-]} \\ q_{\mathrm{b} x}, q_{\mathrm{b} y} & \text { solid discharge (bed load and gravity-induced) } & {\left[\mathrm{m}^{2} / \mathrm{s}\right]} \\ s & \text { relative density of the sediments: } s=\rho_{\mathrm{s}} / \rho_{\mathrm{w}}(\Delta s=s-1) & {[-]} \\ t & \text { time } & {[\mathrm{s}]} \\ \bar{u}, \bar{v} & \text { depth-averaged velocity components along } x \text { and } y & {[\mathrm{~m} / \mathrm{s}]} \\ x, y & \text { space coordinates along the reference axes } & {[\mathrm{m}]} \\ z_{\mathrm{b}} & \text { bed elevation } & {[\mathrm{m}]} \\ \theta_{x}, \theta_{y}, \theta_{z} \text { angle between the reference axes and the vertical direction } & {[-]} \\ \rho_{\mathrm{w}}, \rho_{\mathrm{s}}, \rho_{\mathrm{m}} \text { density of, respectively, water, sediments and the mixture } & {\left[\mathrm{m}^{3} / \mathrm{s}\right]} \\ \tau_{\mathrm{b} x}, \tau_{\mathrm{b} y} & \text { bottom shear stress along } x \text { and } y & {\left[\mathrm{~N} / \mathrm{m}^{2}\right]}\end{array}$

\section{References}

[1] Armanini, A. and G.D. Silvio, A one-dimensional model for the transport of a sediment mixture in non-equilibrium conditions. J. Hydraul. Res., 1988. 26(3): p. 275-292.

[2] ASCE Task Committee on Turbulence Models in Hydraulic Computations, Turbulence modeling of surface water flow and transport: Part I. J. Hydraul. Eng.-ASCE, 1988. 114(9): p. 970-991.

[3] Brufau, P., P. Garcia-Navarro, P. Ghilardi, L. Natale and F. Savi, 1D mathematical modelling of debris flow. J. Hydraul. Res., 2000. 38(6): p. 435.

[4] Caleffi, V. and A. Valiani. A mathematical model for dam-break over movable bed. in Proc. 1st Int. Conf. on Fluvial Hydraulics: River Flow 2002, Louvain-la-Neuve, Belgium, 4-6 September 2002. 2002. Roterdam: Balkema.

[5] Capart, H., Dam-break induced geomorphic flows and the transitions from solid- to fluid-like behaviour across evolving interfaces. 2000, $\mathrm{PhD}$ thesis, Université catholique de Louvain: 208 p.

[6] Dewals, B., Une approche unifiée pour la modélisation d'écoulements à surface libre, de leur effet érosif sur une structure et de leur interaction avec divers constituants. 2006, $\mathrm{PhD}$ thesis, University of Liege: $636 \mathrm{p}$.

[7] Dewals, B.J., S.A. Kantoush, S. Erpicum, M. Pirotton and A.J. Schleiss, Experimental and numerical analysis of flow instabilities in rectangular shallow basins. Environ. Fluid Mech., 2008 (published on-line).

[8] Erpicum, S., Optimisation objective de paramètres en écoulements turbulents à surface libre sur maillage multibloc. 2006, $\mathrm{PhD}$ thesis, University of Liege.

[9] Fäh, R., Numerische Simulation der Strömung in offenen Gerinnen mit beweglicher Sohle. Mitteilungen der Versuchsanstalt für Wasserbau, Hydrologie un Glaziologie, ed. D. Vischer. Vol. 153. 1997, Zürich: ETHZ, $161 \mathrm{p}$.

[10] Fraccarollo, L. and A. Armanini. A semi-analytical solution for the dambreak problem over a movable bed. in Proc. XXVIII IAHR Congress. 1999. Graz, Austria. 
[11] Fraccarollo, L. and H. Capart, Riemann wave description of erosional dambreak flows. J. Fluid Mech., 2002. 461: p. 183-228.

[12] Fraccarollo, L., H. Capart and Y. Zech, A Godunov method for the computation of erosional shallow water transients. Int. J. Numer. Meth. Fluids, 2003. 41: p. 951.

[13] Froehlich, D.C. IMPACT Project field tests 1 and 2: "blind" simulation by DaveF. in 2nd IMPACT Project Workshop. 2002. Mo-i-Rana, Norway.

[14] Galappatti, G. and C.B. Vreugdenhil, A depth-integrated model for suspended sediment transport. J. Hydraul. Res., 1985. 23(4): p. 359-375.

[15] Köngeter, J. and C. Forkel, Vorlesungsumdruck Hydromechanik III. 2000: Aachen University of Technology, $128 \mathrm{p}$.

[16] Leal, J., R. Ferreira, A. Cardoso and A. Almeida. Overview of IST Group Results on the Sediment Benchmark. in Proc. 3rd IMPACT Project Workshop. 2003. Louvain-la-Neuve, Belgium.

[17] Leal, J.G.A.B., R.M.L. Ferreira and A.H. Cardoso, Dam-break wave propagation over a cohesionless erodible bed, in Proc. 30th IAHR Congress, J. Ganoulis and P. Prinos (eds). Vol. C. 2003, IAHR: Thessaloniki. p. 261-268.

[18] Mercier, C., Modélisation tridimensionnelle du transport sédimentaire au large de la côte belge. 2004, Diploma thesis, University of Liege: 75 p.

[19] Paquier, A. Sediment transport models used by Cemagref during Impact project. in Proc. 1st IMPACT Project Workshop. 2002. Wallingford, UK.

[20] Rodi, W., Turbulence models and their application in hydraulics - A stateof-the-art (second revised edition). 1984: Balkema.

[21] Singh, V., Dam breach modeling technology. Water Science and Technology Library. 1996, Dordecht, Bos, London: Kluwer Academic Publishers, $242 \mathrm{p}$.

[22] Spinewine, B. and Y. Zech. Dam-break waves over movable beds: a "flat bed" test case. in Proc. 2nd IMPACT Project Workshop. 2002. Mo-I-Rana, Norway.

[23] Takahashi, T. and H. Nakagawa, Flood/debris flow hydrograph due to collapse of a natural dam by overtopping. Journal of Hydroscience and Hydraulic Engineering, Japan Society of Civil Engineers, JSCE, 1994. 12(2): p. 41-49.

[24] Valiani, A. and V. Caleffi. Dam break modelling for sediment laden flows. in Int. Symp. on Environmental Hydraulics. 2001. Arizona State University, USA.

[25] van Rijn, L.C., Sediment transport, Part II: suspended load Transport. J. Hydraul. Eng.-ASCE, 1984. 110(11): p. 1613-1641.

[26] van Rijn, L.C., Sediment pick-up functions. J. Hydraul. Eng.-ASCE, 1984. 110(10): p. 1494-1502.

[27] Wang, S.S.Y. and W. Wu. River sedimentation and morphology modeling The state of the art and future development. in Proc. 9th Int. Symposium on River Sedimentation. 2004. Yichang, China.

[28] Woo, H.S., P.Y. Julien and E.V. Richardson, Suspension of large Concentrations of Sands. J. Hydraul. Eng.-ASCE, 1988. 114(8): p. 888-898. 